\title{
In-Situ Studies of Thermal Stability of Core-Frame Cubic Pd-Rh Nanocrystals at Elevated Temperatures
}

\author{
Ning $\mathrm{Lu}^{1}$, Jinguo Wang ${ }^{1}$, Shuifen $\mathrm{Xie}^{2}$, Younan Xia ${ }^{2}$, Moon J. Kim ${ }^{1}$ \\ 1. Department of Materials Science and Engineering, The University of Texas at Dallas, Richardson, \\ Texas 75080 USA \\ 2. The Wallace H. Coulter Department of Biomedical Engineering, Georgia Institute of Technology and \\ Emory University, School of Chemistry and Biochemistry and School of Chemical and Biomolecular \\ Engineering, Georgia Institute of Technology, Atlanta, GA 30332 USA
}

Nanosize metallic particles have long been recognized as important heterogeneous catalytic materials. Recent studies show that the atomic characteristics of metallic nanoparticles, including particle size, shape and surface composition, are critical to catalytic activity and selectivity. It has been proven that the catalytic activities of noble metals are highly dependent on their surface structures. Given that the surface structures of nanocrystals have a strong correlation with their morphologies, the control of nanocrystal morphology has become a central theme of research with an ultimate goal to tune the nanocrystal catalytic performance. Bimetallic nanocubes synthesized by seed-mediated growth have the advantage of coupling the catalytic properties of one metal with those of another metal and form multifunctional nanocrystals. Herein, we demonstrate a potential method to enhance the thermal stability of $\mathrm{Pd}-\mathrm{Rh}$ core-frame nanocubes investigated by in-situ heating transmission electron microscopy.

Pd-Rh bimetallic nanocubes were synthesized by site-specific growth. [1] Transmission electron microscopy (TEM), high-angle annular dark-field scanning (HAADF)-scanning transmission electron microscopy (STEM) and energy dispersive X-ray (EDS) mapping were performed in a JEOL ARM200F with a STEM aberration (Cs) corrector operated at $200 \mathrm{kV}$. In-situ heating experiments were performed using a MEMS-based localized heating specimen holder (by Protochips). Pd-Rh cubes obtained at different stages of a synthesis were investigated at elevated temperatures.

Since the Pd nanocubes start to dramatically degrade at $500{ }^{\circ} \mathrm{C}$, changing into spherical-like shape, we choose $500{ }^{\circ} \mathrm{C}$ as the heating treatment temperature to investigate the thermal stability of $\mathrm{Pd}-\mathrm{Rh}$ core-frame nanocubes. [2] Figure 1 presents the results of the $\mathrm{Pd}-\mathrm{Rh}$ nanocubes obtained in the initial stage of synthesis. Figures 1a-1c show in-situ HAADF-STEM images of Pd-Rh core-frame nanocubes recorded from the same region at room temperature $(\mathrm{RT})$ and $500^{\circ} \mathrm{C}$. The $\mathrm{Pd}-\mathrm{Rh}$ nanocubes maintained the cubic shape very well up to annealing at $500{ }^{\circ} \mathrm{C}$ for 1 hour. The thermal stability of Pd nanocubes is significantly enhanced by coating high melting point metal $(\mathrm{Rh})$ on the corners and edges. Figure $1 \mathrm{~d}$ and 1e show the atomic HAADF-STEM images of typical nanocubes at RT and $500^{\circ} \mathrm{C}$ annealing $1 \mathrm{hr}$, respectively. The atomic numbers of $\mathrm{Pd}$ and $\mathrm{Rh}$ are 46 and 45, respectively. They are very close. Thus, there is no distinct contrast difference between core Pd and frame $\mathrm{Rh}$ in the HAADF images, as shown in Figure 1d-1e. STEM/EDS mapping was used to determine the distributions $\mathrm{Pd}$ and $\mathrm{Rh}$ in the nanocubes at $\mathrm{RT}$ and $500{ }^{\circ} \mathrm{C}$.

In summary, using in-situ heating transmission electron microscopy, we have demonstrated one effective approach to enhance thermal stability of Pd nanocubes at elevated temperatures by coating high melting point metal $\mathrm{Rh}$ on corners and edges to form core-frame bimetallic nanocubes. The $\mathrm{Pd}-\mathrm{Rh}$ core-frame cubes maintained cubic shape after annealing 1 hour at $500{ }^{\circ} \mathrm{C}$. Surface pre-melting of $\mathrm{Pd}$ is 
suppressed by the surface diffusion of $\mathrm{Rh}$ from corners and edges to $\{100\}$ side surface. This strategy of shape stabilization can be extended to the development of other multi-metallic nanocrystals for broad high temperature applications. [2]

\section{References:}

[1] S. F. Xie, N. Lu, Z. X. Xie, J. G. Wang, M. J. Kim and Y. N. Xia, Angewandte ChemieInternational Edition 51 (2012), 10266.

[2] N. Lu, J. G. Wang, S. F. Xie, Y. N. Xia and M. J. Kim, Chemical Communication 49 (2013), 11806. [3] This work was supported by Leading Foreign Research Institute Recruitment Program through NRF funded by MSIP, Korea (2013K1A4A3055679). The synthesis work was supported in part by a grant from the NSF (DMR-1215034) and start-up funds from Georgia Institute of Technology.

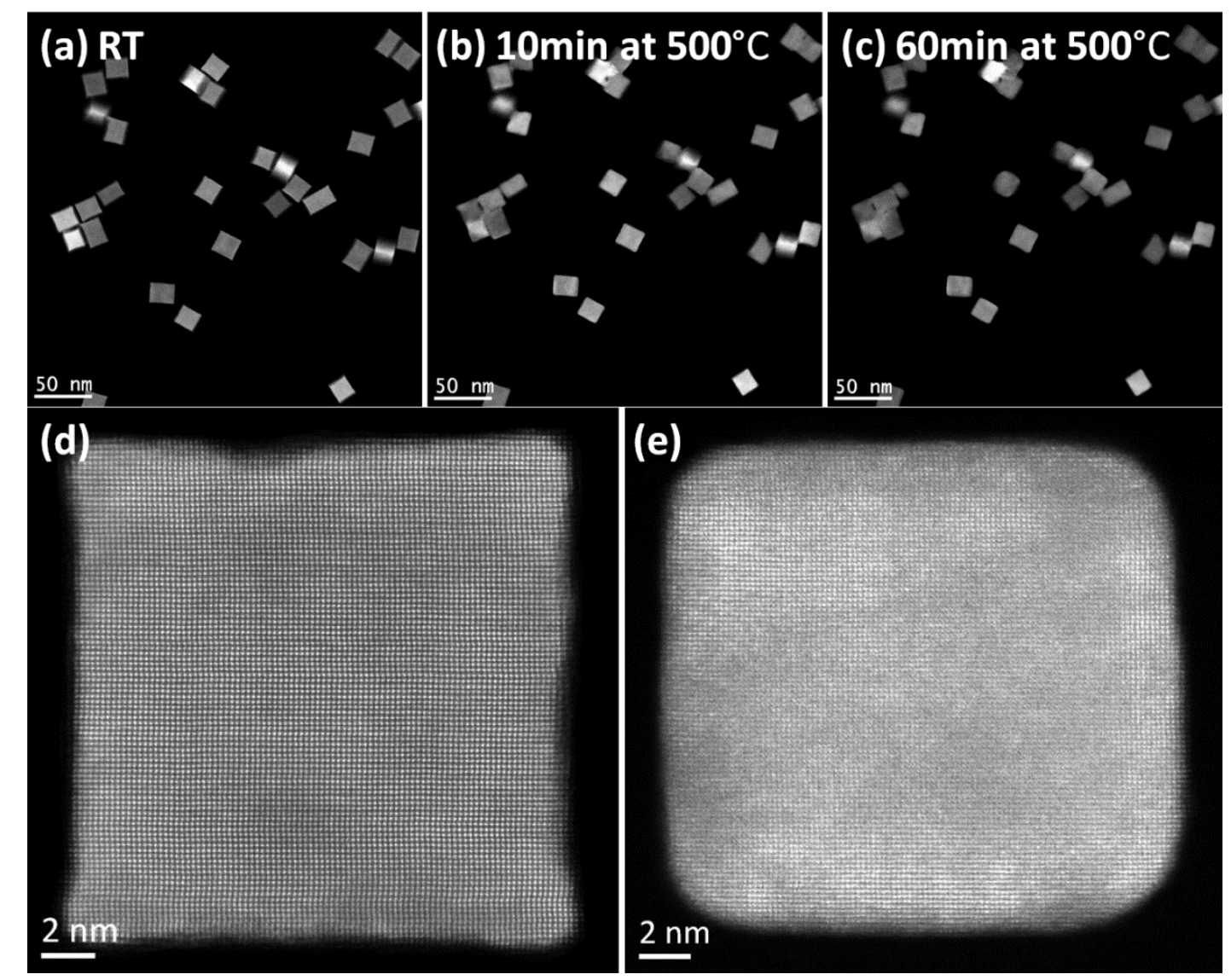

Figure 1. HAADF-STEM images of $\mathrm{Pd}-\mathrm{Rh}$ core-frame nanocubes as synthesized. In-situ images recorded from the same region (a) at room temperature and (b, c) at $500{ }^{\circ} \mathrm{C}$ after different annealing time of $10 \mathrm{~min}$ and $60 \mathrm{~min}$. (d) and (e) are the atomic HAADF-STEM images of typical nanocubes at $\mathrm{RT}$ and $500{ }^{\circ} \mathrm{C}$ annealing $1 \mathrm{hr}$, respectively. 